\title{
Evolusi Hidrogeokimia pada Mataair di Sistem Goa Pindul, Karangmojo, Kebupaten Gunungkidul
}

\author{
Afid Nurkholis, Ahmad Cahyadi dan Setyawan Purnama \\ Departemen Geografi Lingkungan, Fakultas Geografi, Universitas Gadjah Mada \\ Yogyakarta
}

\section{Intisari}

Mataair di kawasan karst umumnya berasal dari aliran airtanah baik yang berasal dari aliran conduit, diffuse ataupun percampuran antara keduanya. Penelitian ini bertujuan untuk mengetahui karakteristik umum evolusi hidrogeokimia pada airtanah yang muncul pada beberapa mataair di Sistem Goa Pindul. Data yang digunakan meliputi data kandungan ion mayor dan kalium di dalam air. Analisis evolusi dilakukan dengan menggunakan diagram piper segi empat yang dikembangkan oleh Kloosterman. Hasil analisis menunjukkan bahwa evolusi hidrogeokimia yang terjadi untuk semua sampel adalah dari tipe semi bikarbonat menjadi tipe air bikarbonat. Hal ini tentunya tidak lepas dari adanya proses pelarutan batuan gamping (karstifikasi) di lokasi kajian.

Kata Kunci: Goa Pindul, Evolusi, Hidrogeokimia, Mataair, Karst

\section{Pendahuluan}

Karst merupakan suatu medan yang memiliki kondisi hidrologi khas (Ford dan Williams, 1989). Kekhasan ini merupakan akibat dari adanya material batuan yang mudah larut dan memiliki porositas sekunder yang berkembang baik (Cahyadi dkk., 2013a; Cahyadi dkk., 2013b). Batuan yang memiliki karakteristik tersebut di antaranya adalah karbonat, gipsum, dan batugaram. Meskipun demikian, batuan karbonat mendominasi bentukan karst karena memiliki sebaran yang paling luas dibandingkan dengan batuan mudah larut lainnya (Haryono dan Adji, 2004).

Kawasan karst dicirikan dengan minimnya/ tidak ditemuinya sungai permukaan dan berkembangnya sistem sungai bawah tanah (Adji, 2011; Cahyadi dkk., 2012, Cahyadi, 2014a). Kondisi ini mengakibatkan masyarakat yang tinggal di kawasan karst seringkali mengalami kesulitan air (Rosaji dan Cahyadi, 2012; Fatchurohman dkk., 2013; Cahyadi, 2014b). Air yang melimpah di sungai bawah tanah belum dapat dioptimalkan akibat 
aksesnya yang sulit dan biaya yang relatif mahal. Oleh karena itu, masyarakat banyak memanfaatkan telaga karst (danau doline) dan mataair untuk memenuhi kebutuhan airnya (Cahyadi, 2014a).

Terbentuknya medan karst tidak dapat dilepaskan dari prosesnya yang seringkali disebut karstifikasi. Menurut Bogli (1980), proses karstifikasi berawal dari air hujan yang jatuh ke permukaan, sehingga terjadi proses fisika dan kimia yang menyebabkan perpindahan massa dan reaksi antara fase udara, air, dan batuan. Sistem perpindahan massa yang terjadi pada medan karst kemudian dikenal dengan sistem $\mathrm{CO}_{2}-\mathrm{H}_{2} \mathrm{O}-\mathrm{CaCO}_{3}$. Tahapan proses pelarutan batugamping dapat dijelaskan seperti berikut ini (Bogli, 1980):

1. Terjadi hujan yang diikuti dengan masuknya gas karbondioksida $\left(\mathrm{CO}_{2}\right)$ di atmosfer ke dalam air melalui proses difusi;

2. Air yang mengandung $\mathrm{CO}_{2}$ bersenyawa membentuk asam karbonat (carbonic acid) dengan reaksi kimia $\mathrm{CO}_{2}$ (di air) $+\mathrm{H}_{2} \mathrm{O}$ $\rightarrow \mathrm{H}_{2} \mathrm{CO}_{3}$, sehingga dapat dikatakan bahwa gas karbondioksida larut dalam air; dan

3. $\mathrm{H}_{2} \mathrm{CO}_{3}$ merupakan asam kuat, maka dapat mengalami proses dissociation (perpecahan) awal, yakni: $\mathrm{H} 2 \mathrm{CO} 3 \rightarrow \mathrm{HCO}_{3}{ }^{-}+\mathrm{H}^{+}$dan proses yang kedua adalah $\mathrm{HCO}_{3}{ }^{-} \rightarrow \mathrm{CO}_{3}{ }^{2-}+\mathrm{H}^{+}$dengan proporsi yang kecil dibawah $\mathrm{pH} \mathrm{8,4;}$

4. Kemudian air dan batuan gamping berinteraksi, terjadi pelepasan ion dengan reaksi pelarutan pelarutan batugamping: $\mathrm{CaCO}_{3} \rightarrow$ $\mathrm{Ca}^{2+}+\mathrm{CO}_{3}$;

5. Selanjutnya, $\mathrm{CO}_{3}^{2-}$ bergabung dengan ion $\mathrm{H}^{+}$yang lepas pada reaksi (3), sehingga $\mathrm{CO}_{3}{ }^{2-}+\mathrm{H}^{+} \longleftrightarrow \mathrm{HCO}_{3}{ }^{-}$.

Sistem Pindul merupakan medan karst yang terletak di Basin Wonosari, Gunungkidul, Daerah Istimewa Yogyakarta. Menurut Agniy (2016), sistem ini memiliki luas $15,44 \mathrm{~km}^{2}$ dengan zona akuifer conduit seluas $1,75 \mathrm{~km}^{2}$ dan akuifer diffuse seluas $13,69 \mathrm{~km}^{2}$. Sistem ini memiliki beberapa sungai bawah tanah, goa dan mataair (Gambar 1). Zona conduit memiliki karakteristik berupa sistem perguaan/ pelorongan hasil pelarutan yang telah berkembang (Cahyadi, 2014a). Hal ini dibuktikan dengan terdapatnya guagua yang saling terhubung membentuk sistem perguaan, yaitu: Gua Asri, Gua Greeng, Gua Emas, Gua Candi, Gua Suruh, Gua Sioyot. dan Gua Pindul (Agniy, 2016). Sementara itu, sistem diffuse dicirikan dengan proses pelarutan yang belum intensif, material akuifer homogen, dan fluktuasi tidak terlalu besar (Cahyadi dkk., 2013b). Karakteristik akuifer diffuse di area kajian dicirikan dengan masih terdapatnya sistem aliran permukaan. 
Mataair juga banyak ditemukan di kawasan Sistem Pindul. Mataair terbentuk sebagai akibat dari aliran bawah permukaan (baik itu diffuse maupun conduit) yang muncul ke permukaan melalui rekahan-rakahan batugamping. Kawasan karst yang memiliki karakteristik sedikitnya aliran permukaan menjadikan pemenuhan kebuthan air masyarakat tergantung dari mataair atau sungai bawah tanah yang muncul di permukaan.

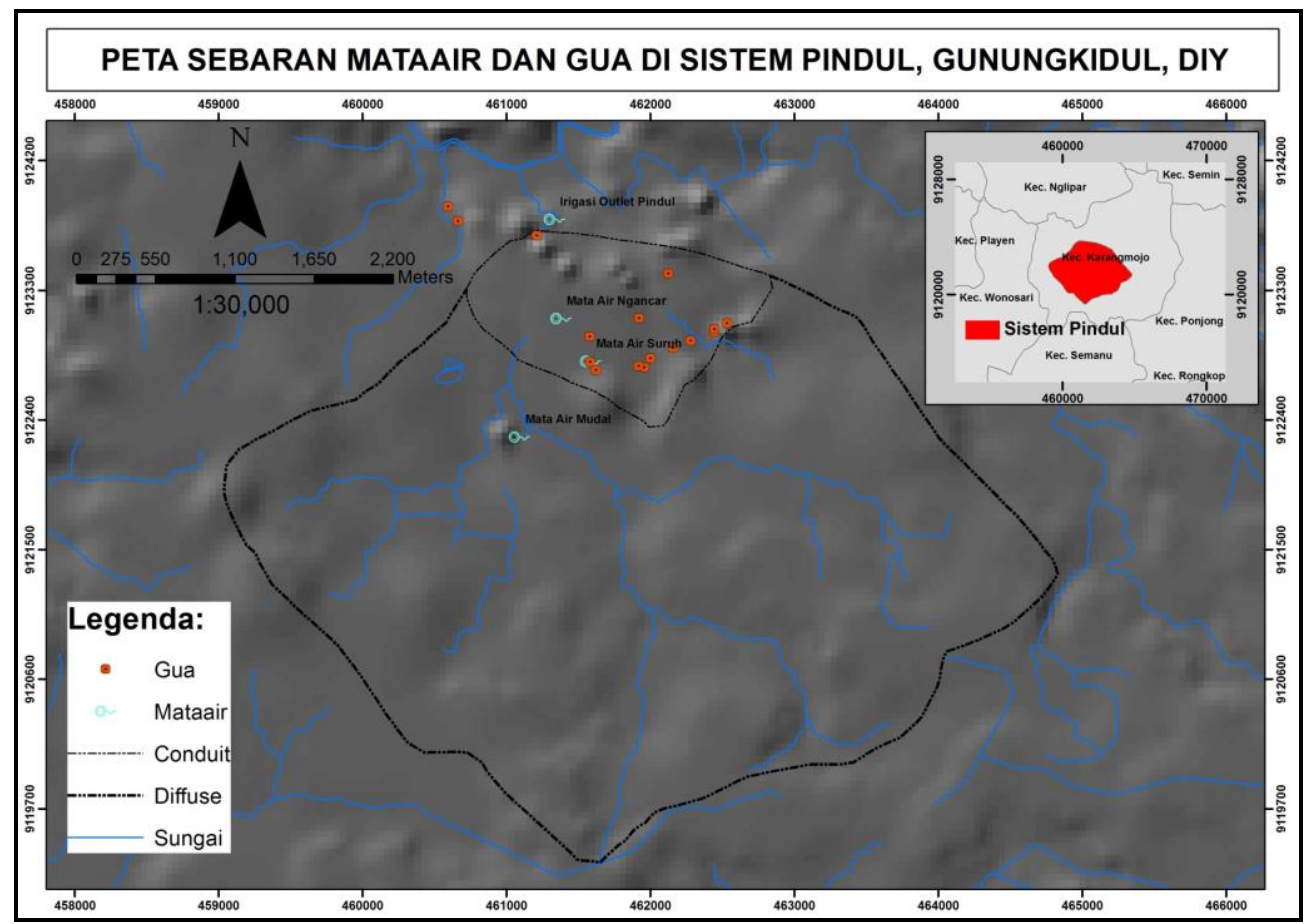

Gambar 1. Sebaran Mataair di Sistem Goa Pindul

Mataair di Sistem Pindul banyak dimanfaatkan oleh masyarakat untuk berbagai kegiatan seperti mencuci, mandi, minum, memasak, serta kegiatan rumah tangga lainnya. Oleh karena itu, kondisi kualitas dari mataair tersebut perlu diperhatikan. Kawasan karst memiliki karakteristik berupa adanya pelarutan batugamping, sehingga air yang ada banyak mengandung ion $\mathrm{Ca}^{2+}$ dan $\mathrm{HCO}_{3}$. Selain itu, aktifitas manusia juga dapat menimbulkan pencemaran yang mengakibatkan air di Sistem Pindul tercemar, sehingga akan menjadi hal menarik untuk dapat mengetahui bagaimana kondisi kualitas mataair di kawasan ini. Penelitian ini akan mengkaji perubahan kualitas mataair atau evolusi hidrogeokimia dari beberapa mataair di Sistem Pindul. Mataair yang menjadi kajian terdiri dari Mataair Mudal, Mataair Ngancar, Mataair Suruh, dan Saluran Irigasi Outlet Pindul. Titik kajian ini dipilih karena banyak dimanfaatkan oleh masyarakat yang dibuktikan 
dengan pembangunan infrasuktur dan adanya kearifan lokal di mataair tersebut.

\section{Metode Penelitian}

\subsection{Alat dan Bahan}

Alat dan bahan yang digunakan di penelitain ini adalah sebagai berikut:

1. Botol Sampel unuk pengambilan sampel air yang selanjutnya dilakukan analisis laboratorium;

2. Separangkat komputer dengan aplikasi Microsoft Office untuk rekap dan analisis data;

3. Global Positioning System (GPS) untuk mengetahui posisi pengambilan sampel; dan

4. Software Arc GIS 10.1 untuk pemetaan dan interpolasi hasil pengukuran.

\subsection{Teknik Pengambilan Data}

Pengambilan data di penelitian ini terdiri dari dua bagian, yaitu pengambilan sampel air di lapangan dan uji kualitas air di laboratorium.

\subsubsection{Pengambilan sampel air}

Sampel air di kajian mataair diambil menggunakan botol sampel. Pengambilan sampel dilakukan masing-masing satu disetiap mataair. Pengambilan sampel tidak memperhatikan kedalaman kolam mataair karena kedalaman yang relatif rendah.

\subsubsection{Uji laboratarium}

Uji laboratorium dilakukan untuk menganalisis kandungan unsur mayor pada sampel air. Parameter unsur mayor yang dialanalisis dalam penelitian ini terdiri dari natrium $\left(\mathrm{Na}^{+}\right)$, kalsium $\left(\mathrm{Ca}^{+}\right)$, magnesium $\left(\mathrm{Mg}^{+}\right)$, klorida $\left(\mathrm{Cl}^{-}\right)$, bikarbonat $\left(\mathrm{HCO}_{3}^{-}\right)$, dan sulfat $\left(\mathrm{SO}_{4}{ }^{-}\right)$. Selain itu ditambahkan unsur minor yakni Kalium $\left(\mathrm{K}^{+}\right)$.

\subsection{Teknik Analisis Data}

\subsubsection{Analisis Keseimbangan Ion}

Menurut Effendi (2003), kandungan ion dalam sampel air seharusnya memiliki jumlah kation dan anion yang sama. Oleh karena itu, analisis keseimbangan ion harus dilakukan sebelum melakukan analisis lebih lanjut (Gilli et al, 2012; Younger, 2007; Aris et al, 2013). Salah satu metode yang digunakan untuk menentukan kulitas data yang dihasilkan dari 
uji laboratorium adalah analisis keseimbangan ion. Analisis keseimbangan ino atau CBE (Charge Balance Error) merupakan metode yang menunjukkan keseimbangan antara ion positif dan ion negatif. Nilai CBE yang diperkenankan adalah memiliki nilai kurang dari 5\% untuk peralatan modern dan kurang dari $10 \%$ untuk analisis laboratorium yang dilakukan secara manual (Hiscock, 2005; Younger, 2007). Perhitungan CBE dilakukan dengan persamaan 1 .

CBE $(\%)=((\Sigma$ Kation $-\Sigma$ Anion $) /(\Sigma$ Kation $+\Sigma$ Anion $)) \times 100$

Perhitungan CBE dilakukan dengan data kandungan ion-ion dalam air dengan satuan miliequivalen/liter (meq/l). Umumnya hasil analisis laboratorium menghasilkan kadungan ion dalam satuan miligram per liter (mg/l), sehingga diperlukan pengeubahan satuan ke meq/l. Konversi satuan dari $\mathrm{mg} / \mathrm{l}$ menjadi meq/l dilakukan dengan persamaan 2 . dan persamaan 3.

$\mathrm{meq} / \mathrm{l}=$ miligram ion $/$ berat ekuivalen

di mana,

berat ekuivalen $=$ berat molekul $/$ valensi ion

\subsubsection{Analisis Evolusi Hidrogeokimia}

Analisis evolusi hidrogeokimia dilakukan dengan menggunakan Diagram Trilinier segi empat atau Diagram Piper segi empat. Diagram ini dikembangkan oleh Kloosterman. Kandungan nilai unsur mayor dari hasil analisis laboratorium dilakukan dengan menge-plot pada pada diagram tersebut. Hasil analisis akan menunjukkan suatu posisi tertentu yang menunjukan evolusi kimia pada mataair Sistem Pindul.Diagram piper biasa sebenarnya dapat pula digunakan untuk analisis evolusi hidrogeokimia (Cahyadi dkk., 2015a; Cahyadi dkk., 2015b). Namun demikian, penggunaan diagram piper segi empat yang dibuat oleh Kloosterman, dirasa lebih mudah dalam aplikasi serta pembacaannya (Agniy dan Cahyadi, 2015). Hal ini karena diagram ini langsung menunjukkan tipe air yang ada.

\section{Hasil dan Pembahasan}

\subsection{Analisis Keseimbangan Ion}

Hasil analisis data yang dilakukan terhadap hasil uji laboratorium menunjukkan bahwa data yang diperoleh memiliki kualitas yang baik. Tabel 1 menunjukkan bahwa nilai CBE dari hasil uji laboratorium masih kurang dari $5 \%$, padahal pengujian dilakukan secara manual. Hasil analisis dalam 
tabel 1 sudah dalam satuan meq/l, sehingga secara langsung dapat dilihat bahwa kation paling dominan adalah Kalsium, sedangkan anion paling dominan adalah Bikarbonat. Hal ini tentunya karena sampel diambil pada wilayah berbatuan gamping.

Tabel 1. Hasil Analisis Kandungan Ion Mayor dan CBE

\begin{tabular}{|c|c|c|c|c|c|c|c|c|c|}
\hline \multirow[t]{2}{*}{ No. } & \multirow[t]{2}{*}{ Mataair } & \multicolumn{4}{|c|}{ Kation (meq/l) } & \multicolumn{3}{|c|}{ Anion (meq/l) } & \multirow{2}{*}{$\begin{array}{l}\text { CBE } \\
(\%)\end{array}$} \\
\hline & & $\mathrm{Na}^{+}$ & $\mathbf{K}^{+}$ & $\mathrm{Ca}^{2+}$ & $\mathrm{Mg}^{2+}$ & $\mathrm{Cl}^{-}$ & $\mathrm{HCO}_{3}^{-}$ & $\mathrm{SO}_{4}^{-}$ & \\
\hline S1 & $\begin{array}{l}\text { Irigasi Outlet } \\
\text { Goa Pindul }\end{array}$ & 0,827 & 0,026 & 5,147 & 0,515 & 0,268 & 6,171 & 0,042 & 0,26 \\
\hline S2 & Mudal & 1,001 & 0,051 & 5,701 & 0,475 & 0,251 & 6,799 & 0,042 & 0,96 \\
\hline S3 & Suruh & 0,870 & 0,026 & 4,751 & 0,634 & 0,265 & 6,299 & 0,021 & $-2,36$ \\
\hline S4 & Ngancar & 0,827 & 0,026 & 5,266 & 0,871 & 0,265 & 6,499 & 0,042 & 1,33 \\
\hline
\end{tabular}

Sumber: Analisis Data

\subsection{Evolusi Hidrogeokimia}

Analisis evolusi hidrogeokimia di penelitian ini dilakukan menggunakan Diagram piper segi empat yang dikembangkan oleh Kloosterman. Data sampel air dikelompokkan terlebih dahulu sebelum dilakukan plot seperti ditunjukkan pada Tabel 2. Hasil analisis menunjukkan bahwa keempat sampel menunjukkan arah evolusi yang sama, yaitu dari air semibikarbonat menjadi air bikarbonat (Gambar 2).

Tabel 2. Input Diagram Kloosterman

\begin{tabular}{|l|l|r|r|r|r|}
\hline No & \multicolumn{1}{|c|}{ Mataair } & $\mathbf{N a}^{+}+\mathbf{K}^{+}$ & $\mathbf{C l}^{-}+\mathbf{S O}_{4}{ }^{-}$ & $\mathbf{C a}^{2+}+\mathbf{~ M g}^{2+}$ & \multicolumn{1}{|c|}{$\mathbf{H C O}_{3}^{-}$} \\
\hline S1 & Irigasi Outlet Goa Pindul & 6,6 & 2,4 & 43,6 & 47,5 \\
\hline S2 & Mudal & 7,3 & 2,0 & 43,1 & 47,5 \\
\hline S3 & Suruh & 7,0 & 2,2 & 41,9 & 49,0 \\
\hline S4 & Ngancar & 6,2 & 2,2 & 44,5 & 47,1 \\
\hline
\end{tabular}

Sumber: Analisis Data

Arah evolusi hidrogeokimia yang sama disebabkan oleh kandungan ion mayor yang jumlahnya hampir sama pada keempat sampel. Tabel 2 menunjukkan bahwa kandungan ion $\mathrm{Na}+\mathrm{K}$ berjumlah 6-7\%, kandungan ion $\mathrm{Cl}+\mathrm{SO} 4$ berjumlah sekitar $2 \%$, kandungan ion $\mathrm{Ca}+\mathrm{Mg}$ berjumlah 41$44 \%$, dan ion $\mathrm{HCO} 3$ memiliki kandungan 47-49\% pada keempat sampel.

Mataair di sistem pindul saat ini merupakan air bikarobonat yang sebelumnya merupakan air semibikarbonat. Air bikarbonat memiliki karakteristik berupa tingginya kandungan ion $\mathrm{Ca}^{2+}, \mathrm{Mg}^{2+}$, dan $\mathrm{HCO}_{3}$. Sementara itu, kandungan ion $\mathrm{Ca}^{2+}$ lebih dominan dibandingkan ion $\mathrm{Mg}^{2+} \mathrm{di}$ 
penelitian ini (Tabel 2), sehingga air bikarbonat di mataair Sistem Pindul disebabkan oleh kandungan ion $\mathrm{Ca}^{2+}$ dan $\mathrm{HCO}_{3}^{-}$yang tinggi.

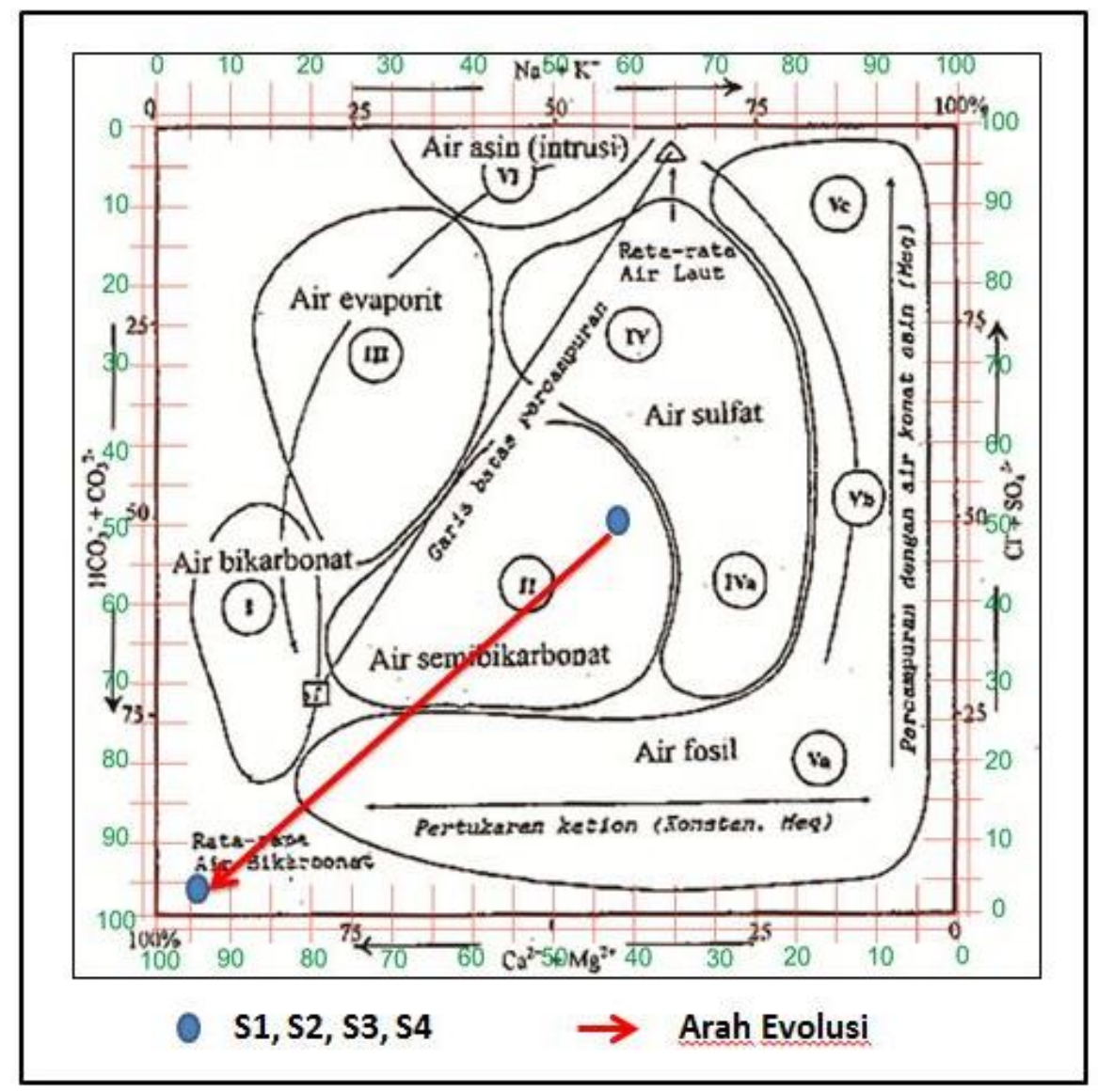

Gambar 2: Evolusi Hidrogeokimia Diagram Kloosterman

Tingginya kandungan ion $\mathrm{Ca}^{2+}$ dan $\mathrm{HCO}_{3}^{-}$di area kajian disebabkan oleh bentanglahan karst yang menyusunnya . Karstifikasi yang terjadi pada area kajian menyebabkan proses pelarutan mineral batugamping terjadi. Menurut Haryono dan Adji (2011) proses karstifikasi secara sederhana diawali oleh larutnya $\mathrm{CO}_{2}$ di dalam air membentuk $\mathrm{H}_{2} \mathrm{CO}_{3}$. Larutan $\mathrm{H}_{2} \mathrm{CO}_{3}$ memiliki sifat tidak stabil, sehingga terurai menjadi $\mathrm{H}^{+}$dan $\mathrm{HCO}^{2-}$. Ion $\mathrm{H}^{+}$inilah yang selanjutnya menguraikan $\mathrm{CaCO}_{3}$ menjadi $\mathrm{Ca}^{2+}$ dan $\mathrm{HCO}^{2-}$. Secara ringkas proses pelarutan dirumuskan dengan reaksi seperti nampak pada persamaan 3 .

$$
\mathrm{CaCO}_{3}+\mathrm{H}_{2} \mathrm{O}+\mathrm{CO}_{2} \rightarrow \mathrm{Ca}_{2}++2 \mathrm{HCO}_{3}^{-}
$$


Hasil analisis menyatakan bahwa sebelum evolusi terjadi jenis air di area kajian merupakan air semibikarbonat. Hal ini menunjukkan bahwa proses karstifikasi telah berlangsung, di mana awalnya memiliki tipe air semibikarbonat yang merupakan ciri dari karakter air hujan, dan kemudian berubah menjadi tipe air bikarbonat karena adanya proses pelarutan batuan gamping. Hal ini diperkuat oleh pendapat Santosa (2010) yang menyebutkan bahwa evolusi kimia airtanah di antaranya disebabkan oleh proses yang terjadi pada airtanah dan lama kontak airtanah dengan lapisan batuan.

\section{Kesimpulan}

Sebagian mataair di Sistem Pindul mengalami evolusi dari air semibikarbonat menjadi air bikarbonat. Hal ini dipengaruhi oleh adanya proses karstifikasi di bentanglahan karst. Proses perubahan ini menunjukkan adanya perubahan dari tipe umum dari air hujan menuju tipe air bikarbonat yang menjadi ciri khas airtanah di kawasan karst.

\section{Pengakuan}

Penelitian ini merupakan bagian dari hibah Penelitian Unggulan Perguruan Tinggi (PUPT) Kementerian Riset, Teknologi dan Pendidikan Tinggi (Kemenristekdikti) tahun 2016 yang berjudul "Karakterisasi Hidrologi dan Banjir di Sungai Bawah Tanah Goa Pindul untuk Pengelolaan Pariwisata Berkelanjutan Berbasis Manajemen Kebencanaan" dengan nomor kontrak 679/UN1-P.III/LT/DIT-LIT/2016.

\section{Daftar Pustaka}

Adji, T. N. 2011. Pemisahan Aliran Dasar Bagian Hulu Sungai Bribin pada Aliran Gua Gilap, di Kars Gunung Sewu, Gunung Kidul, Yogyakarta. Jurnal Geologi Indonesia, 6(3): 165-175.

Agniy, R.F. dan Cahyadi, A. 2015. Analisis Evolusi Hidrogeokimia Airtanah di Sebagian Mataair Karst Kabupaten Rembang Bagian Selatan. Prosiding Seminar Nasional Innovation in Environmental Management. Semarang: Program Pascasarjana Universitas Diponegoro.

Agniy, Romza F. 2016. Kajian Hidrogeologi Karst Sistem Gua Pindul, Kecamatan Karangmojo, Kabupaten Gunungkidul. Skripsi. Fakultas Geografi UGM.

Aris, A.Z.; Praveena, S.M. dan Isa, N.M. 2013. Groundwater Composition and Geochemical Controls in Small Tropical Island of Malaysia: A 
Comparative Study. dalam Wetzelhuetter, C. 2013. Groundwater in The Coastal Zones of Asia-Pacific. Dordrecht: Springer.

Bogli. 1980. Karst Hydrology and Physical Speleology. Springer. Verlag.

Cahyadi, A.; Marfai, M.A.; Nucifera, F. dan Rahmadana, A. 2012. Perencanaan Penggunaan Lahan di Kawasan Karst Berbasis Kemampuan Lahan dan Pemetaan Kawasan Lindung Sumberdaya Air: Studi Kasus di Kecamatan Ponjong, Kabupaten Gunungkidul, D.I. Yogyakarta. Prosiding Seminar Nasional Science, Engineering and Technology. Malang: Program Magister dan Doktor Fakultas Teknik Universitas Brawijaya.

Cahyadi, A.; Ayuningtyas, E.A. dan Prabawa, B.A. 2013a. Urgensi Pengelolaan Sanitasi dalam Upaya Konservasi Sumberdaya Air di Kawasan Karst Gunungsewu Kabupaten Gunungkidul. Indonesian Journal of Conservation, 2(1): 23-32.

Cahyadi, A.; Pratiwi. E.S. dan Fatchurohman, H. 2013b. Metode-metode Identifikasi Karakteristik Daerah Tangkapan Air Sungai Bawah Tanah dan Mataair Kawasan Karst: Suatu Tinjauan. dalam Marfai, M.A. dan Widyastuti, M. 2013. Pengelolaan Lingkungan Zamrud Khatulistiwa. Yogyakarta: Pintal. Hal: 50 -61.

Cahyadi, A. 2014a. Keunikan Hidrologi Kawasan Karst: Suatu Tinjauan. dalam Cahyadi, A.; Prabawa, B.A.; Tivianton, T.A. dan Nugraha, H. 2014. Ekologi Lingkungan Kawasan Karst Indonesia: Mejaga Asa Kelestarian Kawasan Karst Indonesia, Edisi 2. Yogyakarta: Deepublish. Hal: $1-13$.

Cahyadi, A. 2014b. Sumberdaya Lahan Kawasan Karst Gunungsewu. dalam Cahyadi, A.; Prabawa, B.A.; Tivianton, T.A. dan Nugraha, H. 2014. Ekologi Lingkungan Kawasan Karst Indonesia: Mejaga Asa Kelestarian Kawasan Karst Indonesia, Edisi 2. Yogyakarta: Deepublish. Hal: $102-113$.

Cahyadi, A.; Agniy, R.F. dan Suhana, S.N. 2015a. Karakterisasi Hidrogeokimia Airtanah untuk Analisis Genesis Airtanah di Pulau Koral Sangat Kecil. Prosiding Seminar Nasional Ke-1 dalam Pengelolaan Pesisir dan Daerah Aliran Sungai. Yogyakarta: Magister Perencanaan Pengelolaan Pesisir dan Daerah Aliran Sungai, Fakultas Geografi, Universitas Gadjah Mada.

Cahyadi, A.; Adji, T.N. dan Marfai, M.A. 2015b. Analisis Evolusi Hidrogeokimia Airtanah di Pulau Koral Pramuka, Kepulauan Seribu. Prosiding Seminar Nasional Geografi. Surakarta: Universitas Muhammadiyah Surakarta. 
Effendi, H. 2003. Telaah Kualitas Air: Bagi Pengelolaan Sumberdaya dan Lingkungan Perairan. Yogyakarta: Kanisius.

Fatchurohman, H.; Cahyadi, A.; Nugraha, H. dan Wacano, D. 2013. Strategi Adaptasi Masyarakat Terhadap Bencana Kekeringan di Kawasan Karst Kecamatan Panggang, Kabupaten Gunungkidul. dalam Sudarmadji; E. Haryono; Adji, T.N.; Widyastuti, M.; Harini, R.; Nurjani, E.; Cahyadi, A. dan Nugraha, H. (editor). Ekologi Lingkungan Kawasan Karst Indonesia: Menjaga Asa Kelestarian Kawasan Karst Indonesia. Deepublish. Yogyakarta.

Ford, D. and William, P., 2007. Karst Hydrogeology and Geomorphology. John Wiley \& Sons Ltd, The Atrium, Southern Gate, Chichester.

Gilli, E.; Mangan, C. dan Mudry, J. 2012. Hydrogeology: Objectives, Methods, Applications, diterjemahkan dari Bahasa Perancis oleh Chloe Fandel. Boca Raton: CRC Press.

Haryono, E. dan Adji, T. N. 2004. Pengantar Geomorfologi dan Hidrologi Karst. Yogyakarta: Fakultas Geografi UGM.

Hiscock, K.M. 2005. Hydrogeology: Principles and Practice. Oxford: Blackwell Publishing.

Rosaji, F.S.C. dan Cahyadi, A. 2012. Deteksi Telaga Potensial untuk Pemenuhan Kebutuhan Air Musim Kemarau di Kawasan Karst Menggunakan Data Penginderaan Jauh Multitemporal. Prosiding Simposium Nasional Sains Informasi Geografis. Yogyakarta: Fakultas Geografi UGM.

Santosa. L.W. 2010. Kajian Genesis Bentuklahan dan Pengaruhnya Terhadap Hidrostratigrafi Akuifer dan Hidrogeokimia Sebagai Geoindikator Evolusi Airtanah Bebas pada Bentanglahan Kuarter Kabupaten Kulonprogo Bagian Selatan, Daerah Istimewa Yogyakarta. Disertasi. Yogyakarta: Fakultas Geografi Universitas Gadjah Mada.

Younger, P.L. 2007. Groundwater in The Environment. Oxford, United Kindom: Blackwell Publishing. 
Makalah ini merupakan bagian dari Buku Seri Bunga Rampai dengan Judul "Hidrologi dan Kepariwisataan Kawasan karst Goa Pindul Kabupaten Gunungkidul" dengan Editor Slamet Suprayogi, Setyawan Purnama, Ahmad Cahyadi, Hendy Fatchurohman. Buku ini diterbitkan oleh Badan Penerbit Fakultas Geografi (BPFG) Universitas Gadjah Mada di Yogyakarta Tahun 2016. Makalah ini termuat dalam Halaman 56-67. 